\title{
Citizen's Adoption of an e-Government System: Validating Extended Social Cognitive Theory (SCT)
}

\author{
Nripendra P Rana \\ School of Management \\ Swansea University \\ Swansea, UK \\ Email:nrananp@gmail.com \\ Yogesh K Dwivedi \\ School of Management \\ Swansea University \\ Swansea, UK \\ Email: ykdwivedi@gmail.com
}

\begin{abstract}
By employing an extended social cognitive theory, this study examines factors (such as outcome expectation, affect, anxiety, self-efficacy and social influence) influencing intention to adopt an electronic government system called online public grievance redressal system (OPGRS) in context of India. The extended social cognitive theory (SCT) was validated using 419 responses collected from eight selected cities in India. The empirical outcomes of the proposed model indicated the significant relationships of seven hypothesised relationships between six constructs. This is the first study, which has used the SCT model to understand the adoption of an e-government system. The policy implication provided in this research can help the government to improve upon the effectiveness and quality of the system and the level of social impact on the users by employing the project champions. It also helps in enhancing their positive feelings toward adopting this system and fully utilise the potential of the OPGRS as a useful tool toward a transparent and corruption free society.
\end{abstract}

Keywords: E-Government, OPGRS, Adoption, SCT, Citizens, SEM, India 


\section{Introduction}

Many governments have enriched the infrastructure and services provided to their citizens (Kim et al., 2007). The introduction of electronic government (e-government) is a move undertaken by governments to become more service oriented and focused toward the implementation of the widespread digital services through one stop points of access for citizens (Anthopoulos et al., 2007). Though e-government provides obvious benefits to governments, professionals, and organisations (Venkatesh et al., 2014), it is citizens who are actually predicted to receive a number of benefits (Jaeger, 2003). Looking at this aspect, one of the most significant requirements of citizen's day-to-day life are their grievances against the government systems, officials, organisations, and bureaucratic structure. As governments develop e-government systems to deliver services to the people, there is a need for evaluation efforts that could examine their effectiveness (Wang and Liao, 2008) in terms of their adoption. Furthermore, except for a few studies (e.g., Rana et al., 2013, 2014, 2015; Venkatesh et al., 2014), the most of the research do not specifically focus on developing countries (Venkatesh et al., 2014). The OPGRS is one such e-government system which is primarily meant for addressing the grievances, issues, and problems of citizens' everyday life and gets them resolved online by the high-level government officials designated for it. It provides enormous benefits to the people by resolving their problems without much concern. 
Grievance redress mechanism is a part of the machinery of any administration. No government can claim to be answerable, responsive, and citizen-friendly unless it establishes a capable and effective grievance redress mechanism. In fact, the grievance redress mechanism of any organisation is an estimate to examine its efficiency and effectiveness as it provides significant feedback on the working of the administration. The grievances from public are accepted at various points in the Government of India. There are mainly two designated agencies in the central government of India handling these grievances namely Department of Administrative Reforms and Public Grievances and Directorate of Public Grievances. The public grievance redress mechanism in India functions on a decentralised basis. An officer of the level of Joint Secretary is designated as the Director of Grievances of the Ministry, Department, or Organisation (Rana et al., 2013, 2014). There are currently 20 different ministries, departments, and organisations in Government of India, which come under the Directorate of Public Grievances. These include railways, posts, telecom, urban development, petroleum and natural gas, civil aviation, shipping, road transport and highways, tourism, public sector banks, public sector insurance companies, regional passport authorities etc. (DPG, 2014a).

The major reasons of grievances primarily include the socio-economic reasons such as prevalent corruption in the ministries, government organisations, and bureaucratic systems, which are ubiquitous in the current society. The factors such as lack of awareness and lack of relevant information about whom to complain make this process even more tedious. Looking at this aspect, the OPGRS has been designed and developed to take care of such issues of citizens without stepping into the ministry offices and government organisations or even without knowing sometimes where to go to register complaints. In majority of the cases, the people don't even know who is accountable to listen to their problems. Therefore, the significance of such e-government systems is felt even more for smooth, transparent and 
impartial running of governments. The past performance of this system indicates that it has settled 21,952 (i.e., 74\%) of the overall (i.e., 29,665) complaints received until $31^{\text {st }}$ March 2014 in favor of complaints whereas another $8 \%$ were settled partly in their favor. However, $18 \%$ of the overall complaints were not found sustainable (DPG, 2014b). Although the OPGRS offers several advantages, its adoption is currently low (as it is evident from the above statistics) and hence it is significant to explore the factors influencing its adoption.

Despite such low adoption rate, only a few recent research studies (e.g., Rana et al., 2013; 2014 ; 2015) have yet attempted to examine citizens' adoption behaviour of such an important public administration system. However, none of these studies has proposed any model based on the SCT to analyse the citizen's adoption of such online government services. Realising that the SCT is one of the most important theories of human behavior, it would be useful to examine the adoption of the OPGRS using the model based on the SCT. This is done by validating an extended SCT. The selection of the SCT as a basic model is motivated from the lack of use of this model in the e-government adoption research and also as this model contains all suitable and important constructs which provides some relevant and useful factors to understand individual's adoption behaviour. To do so, this research has validated the extended SCT model accompanied with the additional construct social influence.

The remaining paper is organised as follows: the next section undertakes a brief review of egovernment literature related to the SCT model and the OPGRS system. This would be followed by a brief discussion on the research model development and hypotheses. The next section follows a brief description on research methodology used for this research. Findings are presented and discussed in subsequent sections. Finally, conclusion including limitations and future research directions and implications for theory and practice are presented in the last section.

\section{Literature review}


There are many well-known technology acceptance and success models including the technology acceptance model (Davis, 1989), the theory of reasoned action (Fishbein and Ajzen, 1975), the theory of planned behavior (Ajzen, 1991), the innovation diffusion theory (Rogers, 1995), the IS success models (Delone and Mclean, 1992, 2003), and the unified theory of acceptance and use of technology (UTAUT) (Venkatesh et al., 2003), which have been used across different studies on e-government contexts. However, the theory such as the social cognitive theory (SCT) (Bandura, 1986) has not been fully used in any study to examine the adoption of any e-government systems. However, some of its constructs in their original forms such as self-efficacy and anxiety, and some other in their analogous forms such as outcome expectations (which is similar to usefulness (Compeau and Higgins, 1995; Davis et al., 1989)) and affect (which is similar to attitude toward using technology (Venkatesh et al., 2003)) have been used across a number of studies in e-government adoption research.

Only a few studies (e.g., Loo et al., 2009; Sahu and Gupta, 2007) on e-government adoption have partially used the SCT or its constructs in course of developing some integrated research model. For example, exploring the acceptance of Malaysian government multi-purpose smartcard application, Loo et al. (2009) used anxiety as one of the direct determinants of intention to use the intended system. Arguing on the non-inclusion of anxiety as a direct determinant of intention to use under the UTAUT model (Venkatesh et al., 2003), the authors made it clear that this construct was considered in the proposed research model only because unlike the UTAUT, ease-of-use is not included from the research framework of their research. The findings somehow indicated that the respondents' views on using e-government applications such as MyKad national identity card (NIC) and driving license (DL) were largely disinterested in terms of their anxiety and their subsequent intentions to use such systems. Similarly, analysing the user's acceptance of Indian Central Excise system, Sahu 
and Gupta (2007) developed an integrated research model by adopting two constructs from the SCT namely self-efficacy and anxiety into consideration.

Some studies on e-government systems (e.g., Gorla, 2008, 2009; Rana et al., 2013; 2014; 2015; Rao, 2004) have explored on the grievance related systems. For example, Gorla (2009) discussed an e-government system called 'Lokmitra' in the state of Himachal Pradesh in India. The grievance redressal system clarifies the doubts of citizens on a number of issues and has an e-mail facility to provide communication and supports local language. One another research by Gorla (2008) discussed the 'Gyandoot' project incorporating multifunctionality including recording grievances of citizens and addressing them. The author also discussed the multi-functional project such as 'N-Logue' which also facilitates public grievance redressal by which citizens can interact with government officials in India. Rao (2004) revealed couple of other online grievance redressal systems operated at the state levels in India. The author revealed that the grievance redressal systems called 'Swagat' in Gujarat and one being upgraded in Madhya Pradesh in India were still under development and not fully equipped and functional to serve the citizens of the corresponding states in India. However, the current development of the online grievance redressal system indicates that the system developed by the government of India covers the grievances lodged from 36 states of India against the central and state government departments and officials across the country (PPG, 2013). Based on the data produced by an e-grievance redressal system submitted to it in 2007, Martinez et al. (2009) identified what type of complaints were submitted where and whether there was a relation with areas of multiple deprivations.

Some recent studies (Rana et al., 2013; 2014; 2015) have also explored online grievance systems, but they have used other dominant IS/IT adoption models such as the UTAUT (Rana et al., 2013) and DeLone and McLean (1992, 2003) IS success models (Rana et al., 2014, 2015). However, none of the studies on e-government -have ever used the SCT model 
to understand the role of its factors toward adopting such systems yet. Realising the lack of empirical evidence of this model and importance of the variables of the SCT, this study will analyse the significance of its variables and the overall performance of the extended SCT model in the context of the online grievance system in Indian context.

\section{Research model development and hypotheses}

The theoretical development for this research is primarily based on the SCT model. This is one of the most powerful theories of human behavior (Bandura, 1986). Compeau and Higgins (1995, 1999) implemented and extended the SCT to the context of computer utilisation. This theory mainly studied the computer use but the nature of the proposed research model and the underlying theory allow it to be extended to acceptance and use of an e-government system, which is primarily an information system. The major reason for considering the SCT as a base model is motivated by couple of reasons: Firstly, the constructs used in this model represent all significant variables, which can be analysed as factors responsible for adopting an e-government system. Secondly, as the SCT is relatively an under-represented model in the context of e-government adoption research, it is necessary to understand the significance of its variables and the performance of the overall model in this context. The decision to incorporate one additional construct (i.e., social influence) and to remove an existing construct (i.e., outcome expectation-performance) is based on some logical justifications. Social influence is defined as the level to which an individual perceives that important others believe that he or she should use the system (Venkatesh et al., 2003). As the individual adoption of an e-government system can be influenced considerably by his or her important others in the society, it would be worth assimilating social influence along the basic SCT model. Realising that this e-government system has primarily been developed keeping citizen's perspectives in mind, the social nature of such system, and given that there is a lack 
of a contextual variable in the SCT, social influence will play an essential role toward understanding the adoption of the OPGRS using in the proposed research model. In other words, as the e-government system such as the OPGRS is largely used by the individuals, they are more likely to be influenced by the surroundings and the important others they live with. In such context, the suggestion given by their friends, colleagues, and family hold a significant impact on their decision taking ability. This is the reason why social influence is considered as a significant construct to be added in the proposed model. Further, the SCT model contains two similar constructs namely outcome expectation-performance and outcome expectation-personal. We have discarded the construct outcome expectationperformance from the proposed research model. This construct provides performance-based outcomes of the behaviour. Particularly, performance expectations deal with job-related outcomes (Compeau and Higgins, 1995). However, outcome expectation-personal represents the personal outcomes of the behaviour. Personal expectations deal with the individual esteem and sense of accomplishment (Compeau and Higgins, 1995). As the OPGRS is mainly concerned with individual's personal consequences of behaviour and not concerned with the performance-based outcomes, we planned to retain only outcome expectationpersonal in the proposed research model and therefore we will name it outcome expectation for the sake of simplicity. Even though the nature of this variable is similar to perceived usefulness of the TAM and performance expectancy of the UTAUT, the main reasoning behind retaining the original name of the variable as 'outcome expectation' is to indicate that this study uses the SCT as a basic model to explore the citizen's adoption of the OPGRS system.

Moreover, unlike the SCT model, the construct affect is used as a mediating variable for behavioral intention. The construct affect has been found rooted in attitude toward using technology, which is defined as an individual's overall affective reaction to using a system 
(Venkatesh et al., 2003). The role of attitude in explaining technology acceptance (e.g., Kim et al., 2009; Taylor and Todd, 1995b) in general and e-government adoption (e.g., Chu et al., 2004; Hung et al., 2009; Lu et al., 2010a) in particular is widely acknowledged in the prior literature. The constructs of the proposed model including outcome expectation and selfefficacy are shown to influence intentions to use the OPGRS system through the mediating variable affect. The proposed model also shows that social influence and anxiety directly impact user's behavioral intentions to use the OPGRS system. Moreover, It is also believed that social influence and self-efficacy will impact the outcome expectation. Also, the judgments of individual's ability to use an e-government system to accomplish an intended task (i.e., self-efficacy) are expected to influence individual's increased esteem and sense of achievement (i.e., outcome expectation) and his or her positive or negative feelings toward the system. As the study intends to analyse the e-government adoption using the SCT as a basic model, all the constructs except social influence have been included from this dominant model of human behavior. Derived from Davis et al. (1989) who established that perceived usefulness would influence individual's intention to use an information system through attitude in a voluntary setting, this research also considers to use outcome expectation (a similar construct to perceived usefulness) to influence individual affect (a similar construct to attitude), which in turn can influence one's intention to use an e-government system.

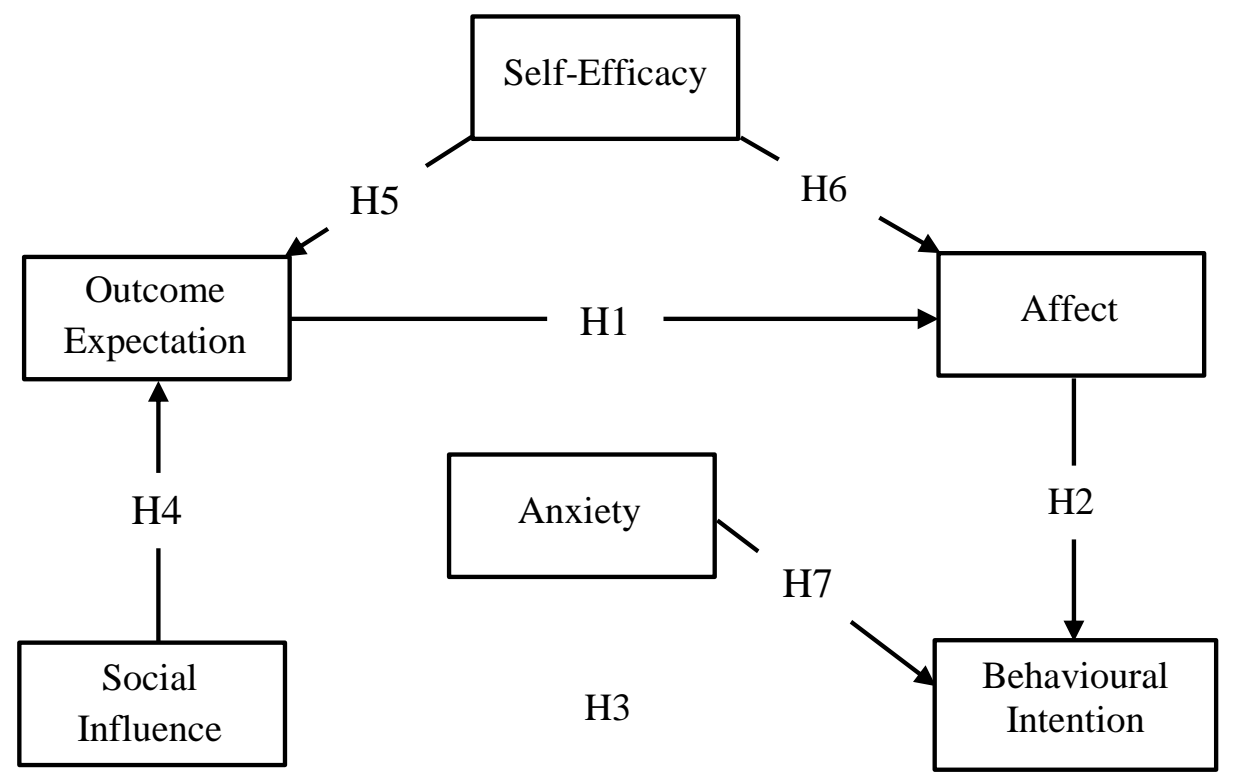


Fig 1. Proposed research model

Considering from the above discussion, the proposed model (see Figure 1) postulates that self-efficacy and outcome expectation will significantly influence affect. Social influence and self-efficacy will significantly influence outcome expectation and social influence, affect, and anxiety will significantly influence behavioral intention. We have provided the supporting studies for all relationships along with the given hypotheses in Table 1.

\begin{tabular}{lll}
\hline Table 1. Summary of research hypotheses & \\
\hline H\# & Hypothesis & Supporting Studies \\
\hline H1 & Outcome Expectation $\rightarrow$ Affect & Chiang (2009), Davis (1989), Hung et al. (2006, \\
& & 2009), Lu et al. (2010), Sahu and Gupta (2007), \\
& & Taylor and Todd (1995a) \\
& & Sahu and Gupta (2007), Venkatesh et al. (2011) \\
H2 & Affect $\rightarrow$ Behavioral Intention & Al-Shafi and Weerakkody (2010), Carter et al. \\
H3 & Social Influence $\rightarrow$ Behavioral Intention & (2008), Sahu and Gupta (2007) \\
& & Gao and Deng (2012), Hu et al. (2011), Koh et al. \\
H4 & Social Influence $\rightarrow$ Outcome Expectation & (2010), Or et al. (2011) \\
& & Seyal and Pijpers (2004), Wang (2002) \\
H5 & Self-Efficacy $\rightarrow$ Outcome Expectation & Fotland (2012), Tohidinia and Mosakhani (2010), \\
H6 & Self-Efficacy $\rightarrow$ Affect & Ye et al. (2006) \\
& & Fotland (2012), Carter et al. (2011), Sahu and \\
H7 & Anxiety $\rightarrow$ Behavioural Intention & Gupta (2007) \\
& &
\end{tabular}

\section{Research methodology}

For the purpose of examining e-government system adoption of the OPGRS, we adopted survey as an appropriate research method. The final questionnaire consisted of total 27 questions including 10 questions from respondent's demographic characteristics and remaining 17 questions (see Appendix A) on six different constructs of the proposed research model. All these questions were multiple-type, close-ended and seven-point Likert scale type questions. Likert scales (1-7) with anchors ranging from 'strongly disagree' to 'strongly agree' were used for all non-demographic questions. Appendix (A) lists all the items for the constructs used in this study.

The sample of the study consists of wide spectrum of respondents from different cities of India including New Delhi, Pune, Mumbai, Bangalore, Patna, Siliguri, and Gangtok. A total of 1500 questionnaires were distributed to respondents through one-to-one and group 
interactions. The respondents were briefed and demonstrated about the functioning of the OPGRS system and in some cases they were given maximum two days of time to complete the questionnaire.

However, some of the questionnaires were made to respond on the spot after the respondents interacted with the systems in a very short period of time. Though most of respondents were computer and Internet literate with a fair amount of experience of interacting with other websites, none of them had a prior experience of using the OPGRS. Realising their prior background and experience of Internet, the shorter time was given to them to get them acquainted with the system to respond the questionnaire. A total of 485 survey questionnaires were received back. The further scrutiny of questionnaires revealed that 66 of them were partially completed and so rejected from the subsequent analysis. Hence, we were left with 419 usable responses, which made our basis for the empirical analysis for measuring the IS success of the OPGRS. The overall response rate was found to be $32.3 \%$ with $27.9 \%$ valid questionnaires.

\section{Research findings}

\subsection{Respondents' demographic profile}

This section analyses demographic data obtained from the respondents (see Table 2). As per the questionnaire results, the average respondent's age ranges from 20 to 34, with males accounting for $67.8 \%$ of the sample and $32.2 \%$ were female. The majority of the population (i.e. $56.1 \%$ ) belongs to student community with a fair representation from public- and private-sector employees (i.e. 29.3\%). As far as the educational qualification of respondents is concerned, $82 \%$ of the total population is having a minimum of graduation degree.

\begin{tabular}{lcc|lcc}
\hline \multicolumn{2}{l}{ Table 2. Demographic Profile of Respondents } & \multicolumn{2}{c}{} \\
\hline Characteristics & Freq & $\mathbf{\%}$ & Characteristics & Freq & \% \\
\hline Gender & & & 1-3 Years & 99 & 23.6 \\
Male & 284 & 67.8 & 4-6 Years & 98 & 23.4 \\
Female & 135 & 32.2 & 7-9 Years & 91 & 21.7 \\
Education & & & >=10 Years & 114 & 27.2 \\
Non-Matriculation & 7 & 1.7 & Internet Access & & \\
Matriculation & 13 & 3.1 & Home & 246 & 42.6
\end{tabular}




\begin{tabular}{lcclcc} 
10+2/Intermediate & 55 & 13.1 & Office & 104 & 18.0 \\
Graduate & 161 & 38.4 & Internet café & 109 & 18.9 \\
Post-Graduate & 169 & 40.3 & College/University & 103 & 17.8 \\
Post-Graduate Research & 14 & 3.3 & Common Service Centre & 10 & 1.7 \\
Occupation & & & No Access & 6 & 1.0 \\
Student & 235 & 56.1 & Internet Experience (in Years) & & \\
Unemployed & 18 & 4.3 & No Experience & 16 & 3.8 \\
Pensioner & 7 & 1.7 & $1-3$ Years & 132 & 31.5 \\
Employee-Public Sector & 29 & 6.9 & $4-6$ Years & 122 & 29.1 \\
Employee-Private Sector & 94 & 22.4 & $7-9$ Years & 80 & 19.1 \\
Self-Employed & 36 & 8.6 & >-10 Years & 69 & 16.5 \\
Computer Access & & & Internet Use Frequency & 12 & 2.9 \\
Home & 273 & 46.4 & Never & 21 & 5.0 \\
Office & 107 & 18.2 & Very Rarely & 39 & 9.3 \\
Internet café & 83 & 14.1 & Rarely & 77 & 18.4 \\
College/University & 100 & 17.0 & Occasionally & 137 & 32.7 \\
Common Service Centre & 12 & 2.0 & Very Frequently & 133 & 31.7 \\
No Access & 13 & 2.2 & Always & & \\
Computer Experience (in Years) & & & & $\mathbf{4 1 9}$ & $\mathbf{1 0 0}$ \\
\hline No Experience & 17 & 4.1 & Total (For each characteristic) \\
\hline
\end{tabular}

The computer and Internet literacy and awareness of the respondents can be judged from their very high computer and Internet experience percentage $(\approx 96 \%)$. This higher frequency is also supported by their computer and Internet access at various places and Internet use frequency, which is very high. Therefore, it is argued that the sample of respondents could be the best-fit potential adopters of the systems such as the OPGRS system.

\subsection{Descriptive Statistics}

Means, standard deviations, and ranges for all six variables are reported in Table 3. The high overall as well as individual items' means for most of the constructs indicate that respondents react favorably to the all the measures directly or indirectly related to behavioral intention. The value for overall mean for anxiety as ' 4.161 ' on the Likert scale [1-7] indicates that respondents are not very sure of concerns being involved with using the OPGRS system.

\begin{tabular}{lcccccc}
\hline Table 3. Mean and standard deviation of constructs and their items \\
\hline Measure & N & Min & Max & Mean & S.D. & $\begin{array}{c}\text { Cronbach's } \\
\text { Alpha }\end{array}$ \\
\hline Outcome Expectation (OE) & 419 & 1 & 7 & $\mathbf{5 . 3 2}$ & $\mathbf{1 . 1 3}$ & \\
OE1 & 419 & 1 & 7 & 5.33 & 1.37 & 0.787 \\
OE3 & 419 & 1 & 7 & 5.38 & 1.31 & \\
OE4 & 419 & 1 & 7 & 5.23 & 1.37 & \\
Affect (AFT) & 419 & 1 & 7 & $\mathbf{5 . 3 0}$ & $\mathbf{1 . 1 3}$ & \\
AF1 & 419 & 1 & 7 & 5.35 & 1.48 & 0.720 \\
AF2 & 419 & 1 & 7 & 5.21 & 1.35 & \\
AF3 & 419 & 1 & 7 & 5.34 & 1.40 & \\
Self-Efficacy (SE) & 419 & 1 & 7 & $\mathbf{5 . 1 2}$ & $\mathbf{1 . 2 4}$ & \\
SE1 & 419 & 1 & 7 & 5.21 & 1.40 & 0.645 \\
SE2 & 419 & 1 & 7 & 5.03 & 1.49 & \\
Social Influence (SI) & 419 & 1 & 7 & $\mathbf{4 . 7 0}$ & $\mathbf{1 . 2 7}$ & 0.715 \\
\cline { 2 - 3 }
\end{tabular}




\begin{tabular}{lllllll} 
& 419 & 1 & 7 & 4.78 & 1.55 & \\
SN2 & 419 & 1 & 7 & 4.94 & 1.49 & \\
SF1 & 419 & 1 & 7 & 4.36 & 1.74 & \\
Anxiety (ANX) & 419 & 1 & 7 & $\mathbf{4 . 1 6}$ & $\mathbf{1 . 2 6}$ & \\
ANX2 & 419 & 1 & 7 & 4.15 & 1.68 & 0.735 \\
ANX3 & 419 & 1 & 7 & 3.83 & 1.73 & \\
ANX4 & 419 & 1 & 7 & 4.13 & 1.48 & \\
Behavioural Intention (BI) & 419 & 1 & 7 & $\mathbf{5 . 2 6}$ & $\mathbf{1 . 2 3}$ & \\
BI1 & 419 & 1 & 7 & 5.31 & 1.50 & 0.796 \\
BI2 & 419 & 1 & 7 & 5.20 & 1.46 & \\
BI3 & 419 & 1 & 7 & 5.27 & 1.40 & \\
\hline
\end{tabular}

Squared pairwise correlations between latent variables, computed using AMOS are reported in Table 4. The square roots of variance extracted estimates (VEE) are reported on the main diagonal of the table. Cronbach's alpha is used to assess the reliability of the scale, which provides an indication of the internal consistency of the items measuring the same construct (Hair et al., 1992; Zikmund, 1994). Each alpha exceeded with the recommended minimum acceptable level of 0.70 (Nunnally, 1978) except for self-efficacy (i.e., 0.645), which is found at the satisfactory level (Floropoulos et al., 2010).

\subsection{Measurement Model}

Convergent and discriminant validity of the scales were validated using confirmatory factor analysis. As recommended by Anderson and Gerbing (1988), a two-step approach was adopted. The measurement aspect of the model is estimated prior to testing the structural model to prevent any interaction between the two models due to measurement error. To measure the unidimensionality, the correlation matrix of a six factor model - outcome expectation, affect, self-efficacy, social influence, anxiety, and behavioral intention -was evaluated. The fit statistics and internal consistency were measured to assess model fit, discriminant validity, and reliability. The fit statistics are reported in Table 4. Due to sensitivity of $\chi^{2}$ to sample size, the root mean square error of approximation (RMSEA) is reported as an assessment of overall fit. The RMSEA takes into account the error of approximation of the population and asks the question "how well would the model, with unknown but with optimally chosen parameter values, fit the population covariance matrix if 
it were available?" (Browne and Cudeck, 1993, pp. 137-138). The values of RMSEA in the range of 0.05 to 0.08 represent reasonable errors of approximation in the population (Browne and Cudeck, 1993). Hu and Bentler (1999) have suggested a value of 0.06 to be indicative of good fit between the hypothesized model and observed data. The model is found to be in the acceptance range $(0.05$ to 0.08$)$ at 0.054 . The goodness-of-fit (GFI) and the adjustedgoodness-of-fit (AGFI) are 0.939 and 0.907 respectively. Because of inconsistencies due to sample characteristics, the comparative fit index (CFI) is reported (Fagan et al., 2003). For the six factor model, the index is 0.951 , which is deemed acceptable.

\begin{tabular}{lll}
\hline \multicolumn{2}{l}{ Table 4. Measurement model estimates: CFA model } \\
\hline Fit Index & CFA Model & Recommendation \\
Chi-Square & 222.437 & N/A \\
Degree of Freedom (DF) & 101 & N/A \\
P & 0.000 & $>0.05$ \\
Chi-Square/DF & 2.202 & $<3.000$ \\
GFI & 0.939 & $>0.90$ \\
AGFI & 0.907 & $>0.80$ \\
CFI & 0.951 & $>0.90$ \\
RMSEA & 0.054 & $0.05<$ RMSEA $<0.08$ \\
\hline
\end{tabular}

Anderson and Gerbing (1988) prescribed convergent validity using three ad hoc tests. Table 5 lists the factor loading, composite reliabilities, and variance-extracted estimates. Standardised factor loadings are indicative of the level of association between scale items and their corresponding latent variables. The loadings were found significant. The composite reliabilities similar to Cronbach's alpha were found exceeding the minimum limit of 0.70 for all constructs but self-efficacy (with CR 0.640). The reliability indicates strong internal consistency for all constructs and a satisfactory level for self-efficacy. This may be due to the fact that only two items were included for this construct (Floropoulos et al., 2010). VEEs are measures for the deviation explained by the latent variable to random measurement error (Netemeyer et al., 1990) and ranged from 0.521 to 0.666 (except self-efficacy whose VEE was found close to 0.50). Netemayer et al. (2003) argued that VEE estimates of 0.45 or higher are an indication of validity for a construct's measure. A number of prior studies (e.g., Fagan et al., 2003; Pagani et al., 2011; Santosh-Vijande et al., 2012; Staples et al., 1999) have 
also reported a moderate though acceptable level of VEEs for some of their constructs including self-efficacy. For example, analysing the management of remote workers in virtual organisations through a self-efficacy theory explanation, Staples et al. (1999) found the VEE for information technology (IT) self-efficacy as 0.47 and reported it in the research and used it as a measure to assess discriminant validity. The reason behind retaining such construct despite its marginally lower VEE is largely due to its significance and role in measuring nonadopter's views on adopting relatively new e-government system such as the OPGRS. Moreover, its slightly minor value does not affect the discriminant validity. These estimates largely exceeded the recommended lower limit of 0.50 (Fornell and Larcker, 1981). Hence, overall tests support the convergent validity of the scales.

\begin{tabular}{lccc}
\hline \multicolumn{4}{l}{ Table 5. Results of confirmatory factor analysis } \\
\hline Construct Items & FL & CR & VEE \\
\hline Outcome Expectation (OE) & & 0.783 & 0.666 \\
OE1 & 0.73 & & \\
OE3 & 0.83 & & \\
OE4 & 0.65 & & \\
Affect (AFT) & & 0.707 & 0.521 \\
AF1 & 0.59 & & \\
AF2 & 0.69 & & \\
AF3 & 0.72 & & \\
Self-Efficacy (SE) & & 0.640 & 0.458 \\
SE1 & 0.63 & & \\
SE2 & 0.74 & & \\
Social Influence (SI) & & 0.739 & 0.593 \\
SN1 & 0.82 & & \\
SN2 & 0.75 & & \\
SF1 & 0.50 & & \\
Anxiety (ANX) & & 0.746 & 0.604 \\
ANX2 & 0.64 & & \\
ANX3 & 0.88 & & \\
ANX4 & 0.57 & & \\
Behavioral Intention (BI) & & 0.784 & 0.666 \\
BI1 & 0.75 & & \\
BI2 & 0.75 & & \\
BI3 & 0.72 & & \\
\hline
\end{tabular}

[Note: CR: Composite Reliability, FL: Factor Loading, VEE: Variance Extracted Estimates]

Anderson and Gerbing (1988) also recommended a test to examine the discriminant validity. The squared correlation between a pair of latent variables should be less than the square root 
of variance extracted estimate of each variable (see Table 6). For example, the factor correlation between AFT and SE is 0.524, which is less than the square root of VEE values for both AFT (i.e., 0.722) and SE (i.e., 0.672). In other words, a construct is considered to be distinct from other constructs if the square root of the average variance extracted for it is greater than its correlations with other latent constructs (Barclay and Smith 1997). Every combination of latent variables was tested, and each pair passed the test, indicating evidence of the discriminant validity of the scales.

\begin{tabular}{lccllll}
\hline \multicolumn{7}{l}{ Table 6. Squared pairwise correlation } \\
\hline Variable & OE & AFT & SE & SI & ANX & BI \\
OE & $0.816^{\mathrm{a}}$ & & & & & \\
AFT & $0.480^{\mathrm{b}}$ & $0.722^{\mathrm{a}}$ & & & & \\
SE & $0.487^{\mathrm{b}}$ & $0.524^{\mathrm{b}}$ & $0.677^{\mathrm{a}}$ & & & \\
SI & $0.498^{\mathrm{b}}$ & $0.310^{\mathrm{b}}$ & $0.367^{\mathrm{b}}$ & $0.770^{\mathrm{a}}$ & & \\
ANX & $0.217^{\mathrm{b}}$ & $0.140^{\mathrm{b}}$ & $0.180^{\mathrm{b}}$ & $0.311^{\mathrm{b}}$ & $0.777^{\mathrm{a}}$ & \\
BI & $0.444^{\mathrm{b}}$ & $0.505^{\mathrm{b}}$ & $0.413^{\mathrm{b}}$ & $0.358^{\mathrm{b}}$ & $0.095^{\mathrm{c}}$ & $0.816^{\mathrm{a}}$ \\
\hline
\end{tabular}

\subsection{Structural Model Testing}

Table 7 illustrates the overall model fit for the structural model testing. The test of overall model fit resulted in a $\chi^{2}$ value of 356.486 with 112 degrees of freedom and a probability value of less than 0.001 . The significant $p$-value indicates the absolute fit of the model is less than desirable. However, as the $\chi^{2}$ test of model fit is absolute to sample size and nonnormality, a better measure of fit is $\chi^{2}$ over degrees of freedom (Belanger and Carter, 2008). The ratio of $\chi^{2}$ over degrees of freedom is close to the suggested 3 to 1 bracket (Chin and Todd, 1995; Gefen, 2000). Typically, researchers also report a number of fit-statistics to examine the relative fit of the data to the model. We report the goodness-of-fit index (GFI), the adjusted GFI (AGFI), and the comparative fit index (CFI). Gerbing and Anderson (1992) found the CFI as one of the most stable and robust fit indices. We also report RMSEA (root mean square error of approximation), which measures the discrepancy per degree of freedom (Steiger and Lind, 1980) and found it very close to the suggested bracket of values. 
The GFI should be at or above 0.90 (Hoyle, 1995), while the AGFI should be at or above 0.80 (Chin and Todd, 1995; Segars and Grover, 1993). The CFI statistics should be at or above 0.90 (Bentler and Bonnett, 1980; Hoyle, 1995). Finally, RMSEA should be below in the range of 0.05-0.08 to represent reasonable errors of approximation (Browne and Cudeck, 1993), but has also been suggested to represent a very good fit if it is below the more restrictive threshold of 0.08 (Belanger and Carter, 2008).

\begin{tabular}{lll}
\hline \multicolumn{2}{l}{ Table 7. Model fit summary for the proposed research model } \\
\hline Fit Index & Structural Model & Recommendation \\
Chi-Square & 356.486 & N/A \\
Degree of Freedom (DF) & 112 & N/A \\
P & 0.000 & $>0.05$ \\
Chi-Square/DF & 3.18 & $<3.000$ \\
GFI & 0.908 & $>0.90$ \\
AGFI & 0.875 & $>0.80$ \\
CFI & 0.901 & $>0.90$ \\
RMSEA & 0.072 & $<0.08$ \\
\hline
\end{tabular}

After establishing the relative adequacy of the model fit, it is appropriate to assess the individual path coefficients corresponding to our hypotheses. The analysis is presented in Table 8 and it supports all seven hypotheses. Outcome expectation and self-efficacy positively influence affect (hypotheses $\mathrm{H} 1$ and H6). Social influence and self-efficacy positively influence outcome expectation (hypotheses H4 and H5). Finally, affect and social influence positively influence behavioral intention (hypotheses $\mathrm{H} 2$ and $\mathrm{H} 3$ ) whereas anxiety negatively influences behavioral intention (hypothesis $\mathrm{H} 7$ ).

\begin{tabular}{llcccc}
\hline \multicolumn{2}{c}{ Table 8. Path coefficients of the relationships } & & & & \\
\hline H\# & Hypothesis & Coefficients & CRT & Sig. & Supported \\
\hline H1 & Outcome Expectation $\rightarrow$ Affect & 0.33 & 4.627 & $* * *$ & YES \\
H2 & Affect $\rightarrow$ Behavioural Intention & 0.58 & 7.831 & $* * *$ & YES \\
H3 & Social Influence $\rightarrow$ Behavioural Intention & 0.26 & 4.307 & $* * *$ & YES \\
H4 & Social Influence $\rightarrow$ Outcome Expectation & 0.51 & 6.543 & $* * *$ & YES \\
H5 & Self-Efficacy $\rightarrow$ Outcome Expectation & 0.46 & 6.274 & $* * *$ & YES \\
H6 & Self-Efficacy $\rightarrow$ Affect & 0.57 & 6.215 & $* * *$ & YES \\
H7 & Anxiety $\rightarrow$ Behavioural Intention & -0.10 & -1.912 & $*$ & YES \\
\hline
\end{tabular}

[Significance: $* * * \mathrm{p}<0.001, * * \mathrm{p}<0.01,{ }^{*} \mathrm{p}<0.05$ ][Note: CRT: Critical Ratio, Sig.: Significance]

Figure 2 presents the validated research model using structural equation modeling technique of AMOS. The path coefficient for each relationship was found significant at the level of 0.001 except for anxiety on behavioral intention which is significant at the level of 0.05 . The 
variance explained on outcome expectation, affect, and behavioral intention was found as $47 \%, 61 \%$, and $46 \%$ respectively.

\section{Discussion}

The purpose of this study is to examine factors influencing the adoption of the OPGRS system using the extended social cognitive theory. We have included an additional construct social influence in the SCT model as this is considered one of the significant factors for measuring adoption of any societal-based information system including e-government system. Hence, the model developed combines six variables such as self-efficacy, outcome expectation, social influence, affect, anxiety, and behavioral intention. The hypotheses results indicated that there are significant links between all structural relationships supporting the hypotheses.

The significant influence of outcome expectation on affect is rooted and influenced from the positive and significant influence of the similar corresponding constructs such as perceived usefulness or performance expectancy on attitude. The variable outcome expectation is originally derived from Bandura's "outcome judgment" (Davis, 1989). It was argued that the relationship between perceived usefulness on attitude has been consistent (Taylor and Todd, 1995a). The positive significance of outcome expectation on affect indicates that system's perceived usefulness and/or individuals' belief to gain advantages by lodging online complaints through the OPGRS system would positively influence their attitude or positive likings for the system. In other words, as outcome expectation in the proposed model is only linked to the individual's personal aspect, it is indicated that person's enhanced efficiency, ability to increase the quality and quantity of output for the same effort by using the OPGRS system would positively influence his or her attitude toward using the system. A number of 
studies (e.g., Fortland, 2012; Hung et al., 2006, 2009; Sahu and Gupta, 2007; Taylor and Todd, 1995a) have supported the positive and significant relationship between the analogous set of constructs i.e. perceived usefulness or performance expectancy and attitude.

Self-efficacy has been found to have a strong and significant relationship with affect. This indicates that even though the individuals are not much exposed to the OPGRS system, their levels of comfort with other information and e-government systems would help them to develop a positive attitude toward using the intended system. As most of respondents surveyed were computer and Internet literate, a positive and significant relationship between these constructs is obvious. Studies (e.g., Fotland, 2012; Tohidinia and Mosakhani, 2010; Ye et al., 2006) on information systems adoption have advocated the significant relationship between these constructs. We also believe that if a person has a positive perception about his or her ability to use a system by oneself, he or she would definitely develop likings or positive attitude for using the system. If the government wants to maximize the use of such systems by the common people who face problems against the government departments and organisations on the day-to-day basis, it needs to provide more facilities by establishing public online support systems. Providing such systems at public places would encourage citizens to use them and develop their comfort levels for using any such systems.

Moreover, self-efficacy was also found to be significant on outcome expectations. Our findings support the earlier work of Igbaria and Iivari (1995) who introduced computer selfefficacy as a factor influencing perceived usefulness in context of examining the computer usage among microcomputer users in Finland. The relationship has also been supported by some studies (e.g., Seyal and Pijpers, 2004; Wang, 2002) on e-government adoption. This research also believes that individual's enhanced beliefs in using the OPGRS system for the accomplishment of the intended task significantly influence one's efficiency, productivity, and performance. 
Social influence was found to significantly influence both outcome expectation and behavioral intention. A number of studies (e.g., Al-Shafi and Weerakkody, 2010; Carter et al., 2008; Sahu and Gupta, 2007) on technology and e-government adoption have supported the significant relationships between social influence and behavioral intention. However, relatively less studies (e.g., Hu et al., 2011; Koh et al., 2010; Or et al., 2011) have explored and supported the relationship between social influence and perceived usefulness or performance expectancy (i.e. similar to the construct outcome expectation). For example, analyzing the acceptance of advanced e-government technology, Hu et al. (2011) indicated that social influence can enhance the impact of perceived usefulness, but it is not able to drive user intentions alone. The present study, however, shows that influence from the important others including friends, colleagues, and family not only enhances individual's efficiency and performance, but also one's intention to use the OPGRS system. In the present societal structure across India, each one of us struggles with the inherent corruption spread across the government departments, organisations, and ministry at state and central government levels. The government should motivate people to encourage their important ones to use such systems to register complaints in order to enhance not only the system's adoption but also the user's effectiveness and performance.

The positive and significant influence of affect on behavioral intention indicates that users with a more positive attitude toward the e-government system are likely to use the system. This relationship is in line with the prior TAM literature (Davis, 1989) and a number of empirical research studies (e.g., Hung et al., 2006, 2009; Sahu and Gupta, 2007; Venkatesh et al., 2011) on technology and e-government adoption. The positive relationship between attitude and behavioral intention implies that, all else being equal, people form intentions to perform behaviors toward which they have positive affect (Davis et al., 1989). For this research, a strong and positive relationship between attitude and behavioral intention 
indicates that positive affect toward using the OPGRS system leads the users to form strong favorable intentions to use it.

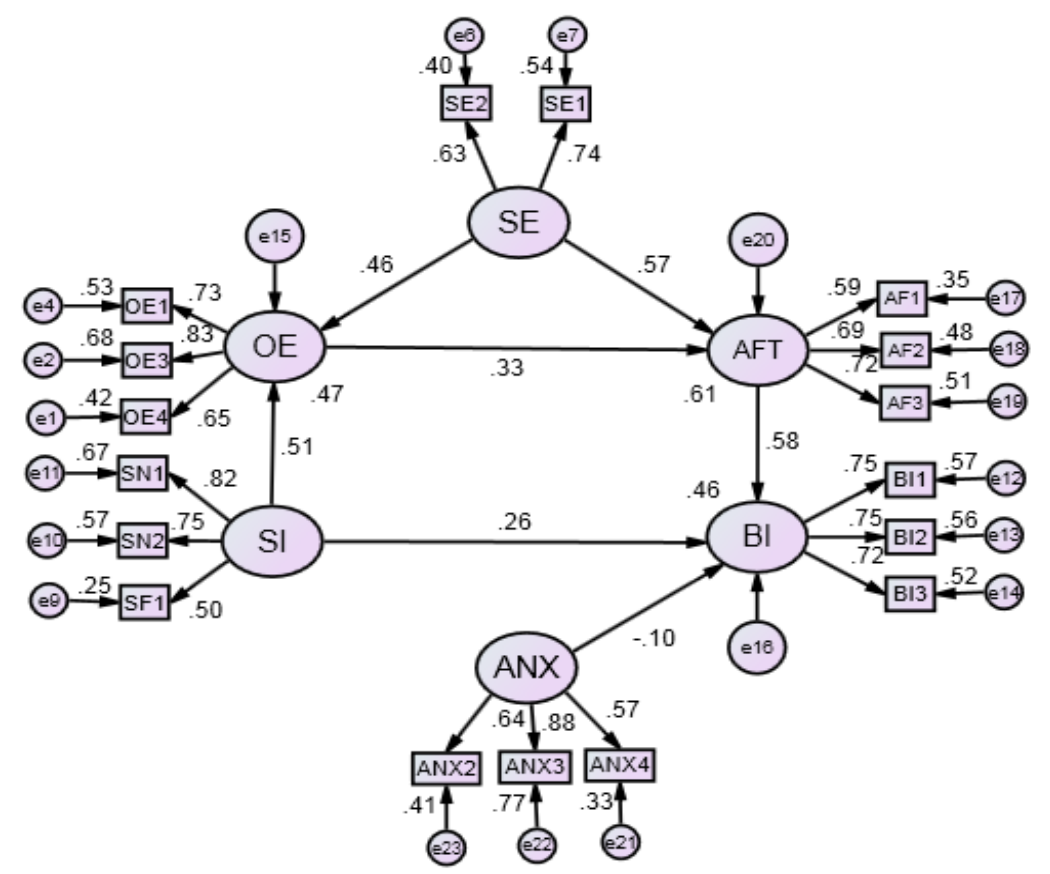

Fig 2. Validated research model

Anxiety has been found as the direct and significant predictor of behavioral intention. This indicates that high evoking of anxious or emotional reactions regarding a behavior (Compeau and Higgins, 1995) results in lower intention to use the OPGRS system. This relationship is also in accordance with the arguments of Venkatesh et al. (2003) who did not include anxiety as the direct determinant of behavioral intention because it is affected or moderated by perceived ease of use. As there is no perceived ease of use is considered in the existing proposed research model, anxiety is found reversely significant on intention to use. The relatively weak path coefficient between anxiety and behavioral intention indicates that users don't feel much anxious about adopting the systems.

\subsection{Implications for theory}

The first theoretical implication of this study is that the SCT model is tested for the first time in context of any research on e-government adoption. Secondly, there has been only a very few empirical research (e.g., Rana et al., 2013, 2014, 2015; Sahu and Gupta, 2007) 
undertaken on e-government systems adoption in context of a developing country like India. The current study has developed a research model and validated it using the primary data. Such research has not been undertaken for a number of well-known and fully functioning egovernment systems including the OPGRS system. This study has given an understanding to researchers toward exploring some factors, which influence the adoption intentions of not only this system but also some other similar systems. Moreover, the extended SCT model presented here can be tested further for different categories of users and using longitudinal data to see the way in which it performs in different circumstances. The empirical testing outcomes of the hypotheses linked to the model can help researchers toward a better understanding of citizen's behavioral intention of the system at large.

Thirdly, although the items of outcome expectations are used along performance expectancy of the UTAUT model, this construct has been hardly ever used independently. It is due to the fact that the SCT model in itself has remained under-represented as far as the e-government adoption research is concerned. The current research has provided not only the context in which it has been used but also its empirical relationship with the other constructs in the proposed research model. Such relationships will provide the researchers to understand its relevance in the e-government research.

\subsection{Implications for policy}

The results will allow the e-government practitioners to realise the factors to give more attention for increasing the citizen's behavioral intentions of the system. The current link of social influence on behavioral intention is although significant but not strong. This indicates that the policy-makers need to give proper attention toward selecting some champions in this area and seek their support to convince their important ones around them. The government can also take proper initiatives toward picking the young unemployed and should give them not only the short-term computer training but also make them aware about the various e- 
government systems (which are beneficial to the citizens). These champions can then take their knowledge and skills and can spread the benefits of the system to the society they belong to. The government of India has recently emphasised and initiated on the skill development program for the unemployed youths, so that they can attain the job oriented skills and can get employment based on skill development and training programs run by the national skill certification and monetary reward scheme of government of India. This could be one of the best ways in which the government can reap the benefits of providing valueadded training to the young champions not only for them to grab better job opportunities but also toward rapidly diffusing some of the most useful online government systems of the likes of the OPGRS. The existence of successful examples and enhanced social influence give rise to a strong feeling that an e-government service is reliable. The significant impact of social influence on outcome expectation indicates that other people's positive comments about the e-government system promote the perception of the effectiveness and quality of such system (Liu et al., 2014). For practitioners, this suggests that proper examples of successful use of egovernment would be an effective solution for enhancing positive word-of-mouth about a service and subsequent promotion of the adoption of such services.

Self-efficacy is also an important factor that positively influences user's outcome expectation and affect. This means that citizens with high self-efficacy are more likely to perceive the egovernment systems easier to use than the citizens with lower self-efficacy. Hence, the government should take more initiatives to equip its citizens to gain higher abilities and selfconfidence and thereby interact with the computer and Internet systems. To do so, the designers of the e-government system should ensure that the built-in help facility for assistance (Venkatesh et al., 2003) to the system is in place. The government can enhance its citizens' self-efficacy by providing them with a hands-on experience on the respective systems so that they can become self-dependent and self-confident to use any such system. In 
addition, the government agency may also focus on a citizen group who has high selfefficacy to use any e-government system (including the OPGRS) as they are more likely potential users of e-government services (Susanto and Goodwin, 2013). Our findings also show that affect (i.e., attitude) played a central role in an individual's intention to use an egovernment system. Specifically, affect has direct impacts on both behavioral intentions which imply that policymakers may find it beneficial to shape the attitudes of individuals for influencing intentions to use an e-government system.

Using this e-government system, the government can bring the greatest impact in terms of improving the life of people living below the line of poverty by solving their issues and giving them justice on time. We must emphasise the value of a free press in publicly exposing the corrupt officials and disseminating news about the trials of such officials. In this way, the concerned officials or organisations that are involved in corrupt practices will more likely to listen to citizens' concerns and less likely to lapse in their duties. This should also imply a strong judicial system, which can protect journalists and help prosecute those who commit crimes (Ekici and Peterson, 2009).

The diffusion of this system in the rural India using the common service centers should be the key priority of the government. Spreading awareness to the people who are always surrounded with lots of grievances and whose complaints are ignored in the government offices could make an optimised use of such systems and the government can start this campaign with a higher note by solving the relevant issues of the larger society that lives in India.

\section{Conclusion}

The purpose of this study is to examine the adoption of the OPGRS system using the extended SCT. We added an additional construct social innovation in the proposed research model. The model hypothesised seven relationships between six selected constructs and was 
found significant. The empirical findings of the study are step forward toward filling the research gap where validation of the SCT model (Compeau and Higgins, 1995) was not performed by any other research study on e-government adoption. The proposed model was found ultimate and acceptable as per the requirements of measurement and structural model testing. As governments at the state and central levels have started spending to implement and maintain a number of e-government initiatives in the country, it is imperative that they should understand the various factors explained above and perform the necessary arrangements to enhance the adoption of the OPGRS system at their levels. This research also helps governments to consider the anxiety levels of their citizens and try all possible ways to minimize them in order to enhance the OPGRS adoption.

\subsection{Limitations and Future Research Directions}

Even though we have systematically developed and validated the extended social cognitive theory for an e-government system adoption, this study has got some limitations. Firstly, the exploration of an extended SCT model has been validated with regard to the potential adopters of the OPGRS system. Hence, the caution needs to be taken while generalising its findings to adopters of the system. Secondly, the model only explains $46 \%$ variance explained on behavioral intentions. The future research might explore some more additional constructs (such as perceived ease of use, trust, facilitating conditions etc.) in order to enhance overall variance of the model on behavioral intentions. Thirdly, the study has not validated this system for specific cultural and geographical contexts. Future research can dig out more on these aspects. Finally, this study has performed empirical investigation of the proposed research model considering the one time cross-sectional data collected from different categories of potential users such as students, employees, unemployed people, housewives, and elderly citizens from various cities of the country. The future research can 
validate the performance of the proposed model separately for students and professionals may be through the longitudinal data.

\section{Appendix A. Description of the final survey items}

\section{Outcome Expectation (OE)}

OE1. If I use the online public grievance redressal system, I will increase my effectiveness OE3. If I use the online public grievance redressal system, I will increase the quality of output

OE4. If I use the online public grievance redressal system, I will increase the quantity of output for the same amount of effort

\section{Affect (AFT)}

AF1. I would like lodging complaint using the online public grievance redressal system

AF2. I look forward to those aspects of lodging complaint that require me to use the online public grievance redressal system

AF3. Using the online public grievance redressal system would be interesting to me

\section{Self-Efficacy (SE)}

SE1. I would feel comfortable while using the online public grievance redressal system on my own

SE2. If I wish, I could easily operate the online public grievance redressal system on my own Anxiety (ANX)

ANX2. It scares me to think that I could lose a lot of information using the online public grievance redressal system by hitting the wrong key

ANX3. I hesitate to use the online public grievance redressal system for fear of making mistakes I cannot correct

ANX4. The online public grievance redressal system would be somewhat intimidating to me

Social Influence (SI)

SN1. People who influence my behaviour think that I should use the online public grievance redressal system

SN2. People who are important to me think that I should use the online public grievance redressal system

SF1. I would use the online public grievance redressal system because of the certain section of people who use the system

\section{Behavioral Intention (BI)}

BI1. I intend to use the online public grievance redressal system

BI2. I predict that I would use the online public grievance redressal system

BI3. I plan to use the online public grievance redressal system in the near future

\section{Reference}

Ajzen, I. (1991). The theory of planned behavior. Organizational Behavior and Human Decision Processes, 50(2), 179-211.

Al-Shafi, S., \& Weerakkody, V. (2010). Factors affecting e-government adoption in the state of Qatar. European and Mediterranean Conference on Information Systems, Abu Dhabi, UAE. 
Anderson, J.C., \& Gerbing, D.W. (1988). Structural equation modeling in practice: A review and recommended two-step approach. Psychological Bulletin, 103(3), 411-423.

Anthopoulos, L.G., Siozos, P., \& Tsoukalas, I.A. (2007). Applying participatory design and collaboration in digital public services for discovering and re-designing e-Government services. Government Information Quarterly, 24(2), 353-376.

Bandura, A. (1986). Social foundations of thought and action: A social cognitive theory. Englewood Cliffs, NJ: Prentice-Hall.

Barclay, D.W., \& Smith, J.B. (1997). The effects of organizational differences and trust on the effectiveness of selling partner relationships. Journal of Marketing, 61(1), 3-21.

Belanger, F., \& Carter, L. (2008). Trust and risk in e-government adoption. The Journal of Strategic Information Systems, 17(2), 165-176.

Bentler, P., \& Bonett, D. (1980). Significance tests and goodness of fit in the analysis of covariance structures. Psychological Bulletin, 88(3), 588-606.

Browne, M.W., Cudeck, R. (1993). Alternative ways of assessing model fit. In: Bollen, K.A., Long, S. (Eds.), Testing Structural Equation Models. Sage, Newbury Park, CA, 136-162.

Carter, L., Schaupp, L.C., \& Evans, A. (2008). Antecedents to e-File adoption: The US perspective. Hawaii International Conference on System Sciences, 216-216.

Carter, L., Schaupp, L.C., \& McBride, M.E. (2011). The US e-File Initiative: An Investigation of the Antecedents to Adoption from the Individual Taxpayers' Perspective. $e$ Service Journal, 7(3), 2-19.

Chiang, L. (2009). Trust and security in the e-voting system. Electronic Government, an International Journal, 6(4), 343-360.

Chin, W.W., \& Todd, P.A. (1995). On the use, usefulness, and ease of use of structural equation modeling in MIS research: A note of caution. MIS Quarterly, 19(2), 237-246.

Chu, P-Y., Hsiao, N., Lee, F.W., \& Chen, C.W. (2004). Exploring Success factors for Taiwan's government electronic tendering system: Behavioral perspectives from end users. Government Information Quarterly, 21(2), 219-234.

Compeau, D.R., \& Higgins, C.A. (1995). Computer Self-Efficacy: Development of a Measure and Initial Test. MIS Quarterly, 19(2), 189-211.

Compeau, D.R., Higgins, C.A., \& Huff, S. (1999). Social cognitive theory and individual reactions to computing technology: A longitudinal study. MIS Quarterly, 23(2), 145-158.

Davis F.D., Bagozzi R.P., \& Warshaw, P.R. (1989). User acceptance of computer technology: A comparison of two theoretical models. Management Science, 35(8), 982-1002.

Davis, F.D. (1989). Perceived usefulness, perceived ease of use, and user acceptance of information technology. MIS Quarterly, 13(3), 319-339.

DeLone, W.H., \& McLean, E.R. (1992). Information systems success: The quest for the dependent variable. Information Systems Research, 3(1), 60-95.

DeLone, W.H., \& McLean, E.R. (2003). The DeLone and McLean model of information systems success: A ten-year update. Journal of Management Information Systems, 19(4), 930.

DPG (2014a). Directorate of Public Grievances. Cabinet Secretariat, Government of India, Accessed from http://dpg.gov.in/AuthPages/OgCovered.aspx, [Accessed on December 8, 2014]. 
DPG (2014b). Directorate of Public Grievances. Cabinet Secretariat, Government of India, Accessed from http://dpg.gov.in/AuthPages/PastPerform.aspx, [Accessed on December 8, 2014]

Ekici, A., \& Peterson, M. (2009). The Unique Relationship Between Quality of Life and Consumer Trust in Market-Related Institutions among Financially Constrained Consumers in a Developing Country. Journal of Public Policy \& Marketing, 28(1), 56-70.

Fagan, M.H., Neill, S., \& Wooldridge, B.R. (2003). An empirical investigation into the relationship between computer self-efficacy, anxiety, experience, support and usage. Journal of Computer Information Systems, 44(2), 95-104.

Fishbein, M., \& Ajzen, I. (1975). Belief, Attitude, Intention and Behavior: An Introduction to Theory and Research. Reading, MA: Addison-Wesley.

Floropoulos, J., Spathis, C., Halvatzis, D., \& Tsipouridou, M. (2010). Measuring the success of the Greek Taxation Information System. International Journal of Information Management, 30(1), 47-56.

Fornell, C., \& Larcker, D.F. (1981). Evaluating structural equation models with unobservable variables and measurement error. Journal of Marketing Research, 18(1), 39-50.

Fotland, A. I. (2012). Intention to use RFID-enabled services: Theoretical review and case study. MSc Dissertation, NHH Bergen.

Gao, T., \& Deng, Y. (2012). A study on users' acceptance behavior to mobile e-books application based on UTAUT model. $3^{\text {rd }}$ International Conference on Software Engineering and Service Science, 376-379.

Gefen, D. (2000). E-commerce: The role of familiarity and trust. Omega: The International Journal of Management Science, 28(6), 725-737.

Gerbing, D.A., \& Anderson, J.C. (1992). Monte Carlo evaluations of goodness of fit indices for structural equation models. Sociological Methods and Research, 2(2), 132-160.

Gorla, N. (2008). Hurdles in rural e-government projects in India: lessons for developing countries. Electronic Government, an International Journal, 5(1), 91-102.

Gorla, N. (2009). A Survey of Rural e-Government Projects in India: Status and Benefits. Information Technology for Development, 15(1), 52-58.

Hair, J.F., Anderson, R.E., Tatham, R.L. and Black, W.C. (1992). Multivariate data analysis with readings. 3rd edn. New York, NY: Macmillan Publishing Company.

Hoyle, R.H. (1995). The Structural Equation Modeling Approach: Basic Concepts and Fundamental Issues. Sage, Thousand Oaks, CA.

Hu, L-T., \& Bentler, P.M. (1999). Cutoff criteria for fit indexes in covariance structure analysis: Conventional criteria versus new alternatives. Structural Equation Modeling, 6, 155.

Hu, P.J.H., Chen, H., Hu, H.F., Larson, C., \& Butierez, C. (2011). Law enforcement officers' acceptance of advanced e-government technology: A survey study of COPLINK Mobile. Electronic Commerce Research and Applications, 10(1), 6-16.

Hung, S.Y., Chang, C.M., \& Yu, T. (2006). Determinants of user acceptance of the egovernment services: The case of online tax filing and payment system. Government Information Quarterly, 23(1), 97-122. 
Hung, S-Y., Tang, K-Z., Chang, C-M., \& Ke, C-D. (2009). User acceptance of intergovernmental services: An example of electronic document management system. Government Information Quarterly, 26(2), 387-397.

Igbaria, M., \& Iivari, J. (1995). The effects of self-efficacy on computer. OMEGA, 23, 587605.

Jaeger, P.T. (2003). The endless wire: E-government as global phenomenon. Government Information Quarterly, 20(4), 323-331.

Kim, H.J., Pan, G., \& Pan, S.L. (2007). Managing IT-enabled transformation in the public sector: A case study on e-government in South Korea. Government Information Quarterly, 24(2), 338-352.

Koh, C.E., Prybutok, V.R., Ryan, S.D., \& Wu, Y. (2010). A model for mandatory use of software technologies: An integrative approach by applying multiple levels of abstraction of informing science. Informing Science: the International Journal of an Emerging Transdiscipline, 13, 177-203.

Liu, Y., Li, H., Kostakos, V., Goncalves, J., Hosio, S., \& Hu, F. (2014). An empirical investigation of mobile government adoption in rural China: A case study in Zhejiang province. Government Information Quarterly, 31(3), 432-442.

Loo, W.H., Paul H.P., Yeow, P.H.P., \& Chong, S.C. (2009). User acceptance of Malaysian government multipurpose smartcard applications. Government Information Quarterly, 26(2), 358-367.

Lu, C-T., Huang, S-Y., \& Lo, P-Y. (2010). An empirical study of on-line tax filing acceptance model: Integrating TAM and TPB. African Journal of Business Management, 4(5), 800-810.

Martinez, J.A., Pfeffer, K.H., \& van Dijk, T. (2009). The capacity of e-government tools: claimed potentials, unnamed limitations. In Proceeding of the 10th N-AERUS Conference: Challenges to Open Cities in Africa, Asia, Latin America and the Middle East: Shared Spaces within and Beyond, IHS Rotterdam.

Netemeyer, R.G., Boles, J.S., \& McMurrain, R. (1996). Development and Validation of Work-Family Conflict and Family-Work Conflict Scales. Journal of Applied Psychology, 81(4), 400-410.

Netemeyer, R.G., Johnston, M.W., \& Burton, S. (1990). Analysis of role conflict and role ambiguity in a structural equations framework. Journal of Applied Psychology, 75(2), 148157.

Or, C.K., Karsh, B.T., Severtson, D.J., Burke, L.J., Brown, R.L., \& Brennan, P.F. (2011). Factors affecting home care patients' acceptance of a web-based interactive self-management technology. Journal of the American Medical Informatics Association, 18(1), 51-59.

Pagani, M., Hofacker, C.F., \& Goldsmith, R.E. (2011). The influence of personality on active and passive use of social networking sites. Psychology \& Marketing, 28(5), 441-456.

PPG (2013). Portal for Public Grievance, Government of India. Accessed from: http://pgportal.gov.in/Grievance.aspx [on Jan 15, 2014].

Rana, N. P., Dwivedi, Y. K., Williams, M. D., \& Lal, B. (2015). Examining the Success of the Online Public Grievance Redressal Systems: An Extension of the IS Success Model. Information Systems Management, 32, 1-21, DOI: 10.1080/10580530.2015. 983019. 
Rana, N. P., Dwivedi, Y. K., Williams, M. D., \& Weerakkody, V. (2014). Investigating success of an e-government initiative: Validation of an integrated IS success model. Information Systems Frontiers, 1-16, DOI: 10.1007/s10796-014-9504-7.

Rana, N., Williams, M., \& Dwivedi, Y. (2013). Examining Factors Affecting Adoption of Online Public Grievance Redressal System: A Case Of India, UKAIS, University of Oxford, UK.

Rao, T.P.R. (2004). ICT and e-Governance and for Rural Development. Symposium on Governance in Development: Issues, Challenges, and Strategies, Institute of Rural Management, India.

Sahu, G.P., \& Gupta, M.P. (2007). Users' Acceptance of E-Government: A study of Indian central Excise. International Journal of Electronic Government Research, 3(3), 1-21.

Santos-Vijande, M.L., López-Sánchez, J.Á., \& Trespalacios, J.A. (2012). How organizational learning affects a firm's flexibility, competitive strategy, and performance. Journal of Business Research, 65(8), 1079-1089.

Seyal, A.H., \& Pijpers, G.G.M. (2004). Senior government executives' use of the Internet: A Bruneian scenario. Behaviour \& Information Technology, 23(3), 197-210.

Staples, D.S., Hulland, J.S., \& Higgins, C.A. (1999). A Self-Efficacy Theory Explanation for the Management of Remote Workers in Virtual Organizations. Organization Science, 10(6), 758-776.

Steiger, J.H., \& Lind, J.C. (1980). Statistically-based tests for the number of common factors. Paper presented at the Annual Spring Meeting of the Psychometric Society, Iowa City.

Susanto, T.D., \& Goodwin, R. (2013). User acceptance of SMS-based e-government services: Differences between adopters and non-adopters. Government Information Quarterly, 30(4), 486-497.

Taylor, S., \& Todd, P.A. (1995a). Understanding information technology usage: A test of competing models. Information Systems Research, 6(2), 144-176.

Taylor, S., \& Todd, P.A. (1995b). Decomposition and crossover effects in the theory of planned behaviour: A study of consumer adoption. International Journal of Research in Marketing, 12(2), 137-155.

Tohidinia, Z., \& Mosakhani, M. (2010). Knowledge sharing behaviour and its predictors. Industrial Management \& Data Systems, 110(4), 611-631.

Venkatesh, V., Morris, M.G., Davis, G.B., \& Davis, F.D. (2003). User acceptance of information technology: Toward a unified view. MIS Quarterly, 27(3), 425-478.

Venkatesh, V., Sykes, T. A., \& Venkatraman, S. (2014). Understanding e-Government portal use in rural India: Role of demographic and personality characteristics. Information Systems Journal, 24(3), 249-269.

Venkatesh, V., Thong, J.Y., Chan, F.K., Hu, P.J.H., \& Brown, S.A. (2011). Extending the two-stage information systems continuance model: Incorporating UTAUT predictors and the role of context. Information Systems Journal, 21(6), 527-555.

Wang, Y-S. (2002). The adoption of electronic tax filing systems: An empirical study. Government Information Quarterly, 20(4), 333-352.

Wang, Y-S., \& Liao, Y-W. (2008). Assessing eGovernment systems success: A validation of the DeLone and McLean model of information systems success. Government Information Quarterly, 25(4), 717-733. 
Ye, S., Chen, H., \& Jin, X. (2006). An empirical study of what drives users to share knowledge in virtual communities. In Lang, J., Lin, F. and Wang, J. (Eds.), Knowledge Science, Engineering and Management, Springer, Berlin, 563-575.

Zikmund, W.G. (1994). Business research methods. 4th edn. New York, NY: The Dryden Press. 